\title{
Examination and Comparison of Psychological Characteristics of American Football Players and Handball Players
}

\author{
Rıdvan Ekmekçi ${ }^{1, *}$, Bülent Okan Miçooğulları \\ ${ }^{1}$ Faculty of Sport Sciences, Pamukkale University, Turkey \\ ${ }^{2}$ Department of Physical Education \& Sports, Faculty of Education, Nevşehir Hacı Bektaş Veli University, Turkey
}

Copyright $\bigcirc 2018$ by authors, all rights reserved. Authors agree that this article remains permanently open access under the terms of the Creative Commons Attribution License 4.0 International License

\begin{abstract}
In this study, mental toughness and anxiety have been chosen to be compared between male American football and handball players. The present study was carried out to determine and examine the psychological parameters mentioned above and show the importance of these concepts in the process of sport career. Mental toughness (with its sub-dimensions) and anxiety levels of 44 male participants were determined. Twenty-seven of those participants were American football players between 19 and 25 years of age (mean $\pm s$ : age $20.93 \pm 2.25$ years). Their sports experience ranged between 1 and 19 years (mean $\pm s: 10.26 \pm 3.34$ years). The remaining seventeen participants were handball players between 18 and 26 years of age (mean $\pm s$ : age $21.54 \pm 3.31$ years). Their sport experience ranged between 5 and 12 years (mean $\pm s: 9.15$ \pm 4.13 years). Differences between the groups were determined using the "Independent Sample t-test" analysis method using the SPSS 21.0 software. The independent sample t-test results showed that there were significant differences in the total mental toughness (including its sub-dimensions; confidence, constancy and control) and anxiety levels of the two group of players $(p<.05)$. The American football team players' confidence, control, and total mental toughness levels were higher than that of handball players and they had lower level scores for constancy and anxiety levels.
\end{abstract}

Keywords Mental Toughness, Anxiety, High Contact Sports

\section{Introduction}

The general and specific characteristics of sports throughout the world have been well described with physical, anthropometric and bio-motor characteristics that indicate which players can be reached in elite level of a specific sport. Identifying the variables of different sports that characterize athletes is valuable to understand what distinguishes them from other athletes or players [1].

The field of sport psychology increased considerably among athletic competitions and disciplines. Before the appearance of scientific attempts, athletes had to manage the psychological skills by themselves. The role of coaches, managers and other staff is crucial in order to help athletes improve [2]. As such, trainers and sport psychologists around the world believe that future records will be broken mainly due to the increased attention given to the psychological parameters of athletes.

In the literature, data are available on intrinsic physical or physiological factors of American Football (henceforth football) and handball players such as; age, body composition, previous injury, poor muscle strength, flexibility and/or endurance, or poor skill level [3-4-5-6]. However, relatively fewer studies have examined the psychological factors in football and handball [7-8].

Football and handball are sports with the highest amount of collision and, thus, with the highest rate of play and practice difficulty rates among all sports. The combination of the size of the players, the speed of play, the different teams with different roles (separate teams of defense and attack for football) and the complexity of the games (other physical and psychological characteristics) make them attractive [9-10-11].

Contact sports are sports that involve direct contact between participants, leaving an individual susceptible to collisions at close or far range with other participants or sports equipment. For the present study, contact sports were divided into two categories: high contact and low/no contact sports. Based on the literature, high contact sports include ice hockey, rugby, football, handball and lacrosse [12-13]. Low and no contact sports include swimming, track and field, tennis, crew, basketball, wrestling, soccer, 
baseball, skiing and dancing [13-14].

Psychological studies are specializations that seek to understand psychological/mental factors that affect physical and psychological performance sports. At the whole levels of the sport, performance success is consistently differentiated by an athlete's or team's display of psychological qualities and effective use of psychological skills [15]. Some of the most important psychological skills taught are goal setting, relaxation, imagery, self-talk, concentration, confidence, problem-solving, attribution training, anxiety, and emotional control. The identification of factors that influence football and handball performance could provide important information to improve pre-game, in-game and post-game performance criterias.

Scientific researches' results about examining players' psychological characteristics relevant to high contact sports while there are studies that aggressiveness, cope with stress, etc. In their studies, researchers aimed to evaluate or examine psychological characteristics that contributed to the development of successful performance and personal excellence. Particularly, researchers with psychology backgrounds, aimed to examine skills related to high contact sports including; aggressiveness, anxiety, confidence, self-talk, negative thoughts, and so on. Previous studies conducted on different sport branches (Rugby, Boxing, Handball, etc.) found that high contact sport players should have psychological skill qualities in order to enhance their performance and personal growth [16-17-18-19-20-21-22].

The extent of contact that athletes have during their participation in games has an influence on psychological variables such as moral competence, self-confidence, aggression, fear, and so on in a sporting context. It has been argued that sports involving a higher level of contact allow harsh play, which supports aggressive tendencies. Moreover, players in high contact sports have a higher risk of physical or psychological injuries and such type of critical effects may change athletes' or whole teams' technical and tactical game strategies. From this perspective, the importance of mental toughness and anxiety skills clearly emerge. Therefore, the present study aimed to examine chosen psychological skills (mental toughness - anxiety) of the American football and handball players.

\section{Methods}

\section{Participants}

A total of 27 male American football team players between the ages of 19 and 25 who participated in Turkish Universities College League of American Football competition and a total of 17 male Handball team players between the ages of 18 and 26 who participated in Turkish Universities League were the subjects of this study and voluntarily participated. American football players' mean age was $20.93( \pm 2.25)$ years and their sports experience ranged between 1 and 19 years (mean $\pm s: 10.26 \pm 3.34$ years). Handball players' mean age was $21.54( \pm 3.31)$ years and their sports experience ranged between 5 and 12 years (mean $\pm s: 9.15 \pm 4.13$ years).

\section{Measurements}

The Sport Mental Toughness Questionnaire (SMTQ) [23] is a 14-item questionnaire designed to determine athletes' mental toughness levels. Participants respond using a 4-point Likert scale ranging from 1 (representing "not at all true") to 4 (representing "very true") and have an approximate completion time of around 4 minutes. Total scores for SMTQ and for its three subscales (confidence constancy - control) can be calculated. A higher mean score indicates a higher degree of mental toughness. Cronbach's alpha for mental toughness-global in the present research was .75. SMTQ has three sub-dimensions: six items for confidence $(\alpha=0.80)$, four items for constancy $(\alpha=0.74)$, and four items for control $(\alpha=0.71)$.

In the current study, anxiety was measured by trait form of the State-Trait Anxiety Inventory (STAI) which included 20-items [24]. Participants responded to each item according to how they generally felt using a four-point scale with anchors from 1 to 4 representing "Almost Never", "Sometimes", "Often", and "Almost Always" respectively. The original Cronbach's alpha value for the trait anxiety scale was .83. The original scale was developed with the participation of 982 high school and collegiate students and the scale is reported to be reliable (internal consistency 0.80 ) for young players. Reliability and validity of the Turkish version of the State-Trait Anxiety Inventory were determined with the participation of 1534 teenagers and adults and its internal consistency was .94 [25]. Cronbach's alpha for the present study showed an acceptable value of 69 .

\section{Statistical Analysis}

The analysis of the collected data was carried out using SPSS 21.0. The data were screened for normality and outliers, and descriptive statistics for all the outcome measures were expressed as a mean \pm standard deviation. The Levene's test and skewness and kurtosis scores were calculated to determine whether the data were normally distributed and homogeneous before proceeding to statistical procedures. Significant differences between groups were calculated using independent samples t-test.

\section{Results}

The aim of the study was to test whether statistical differences in terms of mental toughness and anxiety 
existed between football team and handball team players. The American football team $(\mathrm{N}=27)$ and the handball team players' $(\mathrm{N}=17)$ mental toughness (with sub-domains) and anxiety level scores were calculated and compared using independent samples t-test. As can be seen in Table 1, the football and handball team players scores were sufficiently normal for conducting a t-test (i.e., skewness $<2.0$ and kurtosis $<9.0[26]$.

Table 1. Descriptive statistics and skewness \& kurtosis results of participants

\begin{tabular}{cccccccc}
\hline & $\mathrm{N}$ & Mean & Std. Deviation & \multicolumn{2}{c}{ Skewness } & \multicolumn{2}{c}{ Kurtosis } \\
\cline { 2 - 8 } & Statistic & Statistic & Statistic & Statistic & Std. Error & Statistic & Std. Error \\
\hline Confidence & 44 & 4.03 & .70 & -.74 & .36 & .20 & .71 \\
Constancy & 44 & 3.24 & .43 & -.38 & .36 & .53 & .71 \\
Control & 44 & 2.93 & .96 & -.15 & .36 & -.74 & .71 \\
Total MT & 44 & 48.50 & 4.19 & .45 & .36 & -.07 & .71 \\
Anxiety & 44 & 29.02 & 7.33 & .00 & .36 & -1.27 & .71 \\
\hline
\end{tabular}

Additionally, the assumption of homogeneity of variances was tested and satisfied via Levene's test (see Table 2).

Table 2. Levene's test results of participants

\begin{tabular}{ccc}
\hline & \multicolumn{2}{c}{ Levene's Test for Equality of Variances } \\
\hline Confidence & F & Sig. \\
Constancy & 2.06 & .16 \\
Control & .36 & .55 \\
Total MT & .17 & .68 \\
Anxiety & .15 & .70 \\
\hline
\end{tabular}

Tests the null hypothesis that the error variance of the dependent variables is equal across groups

The independent samples t-test was associated with a statistically significant effect for all variables (see table 3 ). There were significant differences in the scores of total mental toughness and its' sub-dimensions and anxiety levels between the football team and the handball team players. The football team players' confidence, control, and total mental toughness levels were higher than handball players and they had lower level scores for constancy and anxiety levels. In detail, there was a significant difference in the scores of confidence sub-dimension between the football team $(\mathrm{M}=4.46, \mathrm{SD}=0.44)$ and the handball team $(\mathrm{M}=3.76, \mathrm{SD}=.70) ; \mathrm{t}\left({ }_{42}\right)=-3.66, \mathrm{p}=.00$. After that, there was a low but acceptable significant difference in the scores of constancy sub-dimension between the American football team $(\mathrm{M}=3.07, \mathrm{SD}=0.45)$ and the handball team $(\mathrm{M}=3.34, \mathrm{SD}=.39) ; \mathrm{t}\left({ }_{42}\right)=2.09, \mathrm{p}=.04$. Thirdly, there was a significant difference in the scores of control sub-dimension between the American football team $(M=3.39, S D=.75)$ and the handball team $(M=2.19, S D=0.78) ; t\left({ }_{42}\right)$ $=5.12, \mathrm{p}=.00$. Fourthly, there was a significant difference in the scores of total mental toughness between the American football team $(\mathrm{M}=49.56, \mathrm{SD}=3.80)$ and the handball team $(\mathrm{M}=46.82, \mathrm{SD}=4.33) ; \mathrm{t}\left({ }_{42}\right)=2.20, \mathrm{p}=.03$. Finally, there was a significant difference in the scores of anxiety levels between the American football team $(\mathrm{M}=26.41, \mathrm{SD}=6.89)$ and the handball team $(\mathrm{M}=33.18, \mathrm{SD}=6.12) ; \mathrm{t}\left({ }_{42}\right)=-3.31, \mathrm{p}=.00$.

Table 3. T-test results of psychological characteristics

\begin{tabular}{cccccc}
\hline & \multicolumn{3}{c}{ t-test for Equality of Means } \\
\hline & $\mathrm{F}$ & $\mathrm{Sig}$ & $\mathrm{t}$ & $\mathrm{df}$ & $\mathrm{S}$ \\
Confidence & 2.06 & .158 & -3.66 & 42 & $.00^{*}$ \\
Constancy & .36 & .552 & 2.09 & 42 & $.04 *$ \\
Control & .17 & .682 & 5.12 & 42 & $.00^{*}$ \\
Total MT & .15 & .702 & 2.20 & 42 & $.03 *$ \\
Anxiety & .68 & .413 & -3.31 & 42 & $.00^{*}$ \\
\hline
\end{tabular}

*Significant at $p<.05$ 


\section{Discussion}

Contemporary football and handball are characterized by a considerable degree of direct struggle and the close encounter between the players. In this respect, the branches are similar to what is known as body play. Moreover, those branches are very complex and multi-factorial. In this respect, psychological skills and components that are related to high contact sports like football and handball should be seen as crucial predictors of sportive and personal excellence. Psychological skills possess discriminant technical, tactical and behavioral qualities, and those qualities allow us to differentiate between successful and less successful players [27]. Profiling psychological skills can be a valuable means of identifying talent, classifying strengths and weaknesses, assigning player positions, and helping in the optimal design of psychological skills training programmers [28].

The purpose of the study was to investigate selected psychological skills of players in two different high contact sports. The most consistent observation of this investigation was that a difference in psychological skills exists between the football and handball players. Findings of the study indicate that football team players' confidence, control, and total mental toughness levels are higher than handball players and that they have lower level scores for constancy and anxiety levels. These findings are consistent with the results of Güçlü et al. [29] and Tsutagawa's [30] studies.

The detailed analysis of the results revealed that there are significant differences between the mean scores of the football players and handball players as far as mental toughness and anxiety are concerned. The football players proved better in terms of confidence and control sub-dimensions of mental toughness and their total mental toughness compared to handball players. Mental toughness characterizes the players' values, attitudes, behaviors, and emotions that enable them not only to persevere and overcome any obstacle, adversity, or pressure experienced, but also to maintain concentration and motivation when things are going well to consistently achieve their goals [31]. Researchers indicated that athletes with higher levels of mental toughness expend more effort, cope better with the many demands of the sports they do than their opponents, and set more difficult goals in the face of pressure from a wide range of different stressors. All these results show us the importance of mental toughness in sport performance [32-33-34-35].

It has been found that handball players that the anxiety level is significantly higher than football players. Having less confidence and more anxiety than the football players may be a reason for the failure anxiety which often emanates from thinking that any mistake made may be very hard to compensate for, and which often results in players blaming themselves for any loss of points and thereby losing their confidence. In other words, since the American footballers have man-to-man combat during the game, any personal mistake may impact the team very dearly and may be very hard to compensate for, which increases the competition anxiety and the feeling of density among the players. Another possibility for the difference can be that in handball to score goals, the offensive players attempt to establish an optimal position for the player by fast movements, performing powerful changes in direction, one-on-one action against defensive players and passing the ball using different offensive tactics. In other words, the speed of the game may be reason for this difference [6].

In the literature, there were few studies that made a comparison of different sports about their psychological skill levels. In one of the studies, Güçlü et al.[29] tried to determine the psychological and biochemical parameters of the football players who chose this high-contact sport and to compare those parameters with those of the players of volleyball, a non-contact sport. The results showed significant differences with regards to self-control/ responsibility, competing anxiety, and feeling density in favor of the American footballers. Those results partially support our findings.

From the results, it can be concluded that there were significant differences between the mental toughness and anxiety levels of the football players and those of the handball players. In short, it can be said that the football team players' confidence, control, and total mental toughness levels are higher than handball players and they have lower level scores for constancy and anxiety levels.

In spite of obtaining significant results, there are a number of limitations to this study that should be acknowledged. As explained in the introduction, contact sports are divided into three categories as high, low, and no contact sports. While we have chosen two high contact sports for this study, those two branches were not the only one that could have been examined. Therefore, future studies can investigate whether there is a difference between other types of high contact sports and, thus, the psychological skill profiles of players might be better established. Second, as the variables of the study, we decided to examine whether there was significant differences on two psychological skills; mental toughness and anxiety. The amount of skills that can be examined can be increased in future studies. In future studies and, as such, identification of certain skills for certain psychological skills for certain sports can help the development of skills training interventions.

In spite of these limitations, the present study contributed to the sport psychology literature by examining and providing preliminary results on the psychological skills of high contact sports players as a process of helping officers and sport psychology scientists in their working area. 


\section{REFERENCES}

[1] N. Rogulj, M. Nazor, V. Srhoj, D. Bozin. Differences between competitively efficient and less efficient junior handball players according to their personality traits. Kinesiology; 38(2), 158-163, 2006.

[2] CJ. Gee. How does sport psychology actually improve athletic performance? A framework to facilitate athletes' and coaches' understanding, Behavior Modification; 34 (5): 386-402 doi: 10.1177/0145445510383525, 2010.

[3] M. Buchheit, PM. Lepretre, AL. Behaegel, GP Millet, G. Cuvelier, S. Ahmaidi. Cardiorespiratory responses during running and sport-specific exercises in handball players. Journal of Science \& Medicine Sport; 12 (3): 399-405, 2009.

[4] DJ. Chalmers, A. Samaranayaka, P. Gulliver, B. Mc Noe. Risk factors for injury in rugby union football in New Zealand: a cohort study. British Journal of Sport Medicine; 46(2), 95-102, 2012.

[5] A. Chaouachi, M. Brughelli, G. Levin, N. Boudhina, J. Cronin, K. Chamari. Anthropometric, physiological and performance characteristics of elite team-handball players. Journal of Sport Science; 27, 151-157, 2009.

[6] H. Wagner, M. Gierlinger, N. Adzamija, S. Ajayi, DW Bacharach, SP von Duvillard. Specific physical training in elite male team handball. Journal of Strength \& Conditioning Research; 31(11), 3083-3093, 2017.

[7] S. Schuster, J. Sindik, U. Kavran. Psychological characteristics and traits in male handball players - the application of multidimensional psychological sports talents scale. Hrvatska Športskomed Vjesn; (31), 29-38, 2016.

[8] K. Steffen, AM. Pensgaard, R. Bahr. Self-reported psychological characteristics as risk factors for injuries in female youth football. Scandinavian Journal of Medicine Science \& Sports; 19(3), 442-451, 2009.

[9] LD. Kaplan, PW Jost PW, Honkamp N, Norwig J, West R, Bradley JP. Incidence and variance of foot and ankle injuries in elite college football players. American Journal of Orthopedia; 40 (1), 40-44, 2011.

[10] E. Scase, ME. Magarey, S. Chalmers, M. Heynen, J. Petkov, S. Bailey. The epidemiology of injury for an elite junior Australian Football cohort. Journal of Science Medicine \& Sport; 15(3), 207-212, 2012.

[11] J. Sindik, S. Bauer, AM Cuk. Psychological characteristics and traits in male handball players - optimism, athlete engagement and mental energy. Sport Science Practice Aspire; 13(1), 5-11, 2016.

[12] K. Mouratidou. Determinants of athletes' moral competence: the role of demographic characteristics and sport-related perceptions. Sport Society; 20 (7), 802-815, DOI: 10.1080/17430437.2016.1221926, 2017.

[13] WT. Tsushima, O. Geling, M. Arnold, R. Oshiro. "Are there sub-concussive neuropsychological effects in youth sports? An exploratory study of high- and low-contact sports." Applied Neurology: Children; 5(2), 149-55, 2016.

[14] AW. Kelly. Non-contact sports: Running, Swimming, and
Dance -- Identifying common injuries. Pediatric Annual; 39, 279-85, 2010.

[15] D. Gould, RC Eklund, SA Jackson. 1988 U.S. Olympic wrestling excellence: I. Mental preparation, precompetitive cognition, and affect. The Sport Psychology; 6, 358-382, 1992.

[16] M. Batista \& L. Vaz. Anxiety and determinants of motivation of athletes in rugby on qualifying for the European championship In J. Dosil (Ed.), Libro de Actas del IV Congreso Galego Portugués de Psicologia del Deporte y I Encuentro de la SIPD Ibérica.Pontevedra: Universidad de Vigo [Book of Proceedings of the IV Congress Galego, Portuguese, Psychology of Sport and I Meeting of the SIPD Iberian. Pontevedra, Spain: University of Vigo]; 468-469, 2015.

[17] J. Cote, J. Baker, B. Abernethy. Practice to play in the development of sport expertise, in R. Eklund and G. Tenenbaum (Ed.), Handbook of Sport Psychology, Hoboken, NJ: Wiley. ISBN: 978-0-131965-72-0, 266-294; 2007.

[18] N. Durand-Bush, JH. Salmela, I. Green-Demers. The Ottawa Mental Skills Assessment Tool (OMSAT-3*). Sport Psychology; (15), 1-19, 2001.

[19] MJ Holland, C. Woodcock, J. Cumming, JL Duda. Mental qualities and employed mental techniques of young elite team sport athletes. Journal of Clinical Sport Psychology; (4), 19-38, 2010.

[20] A. Junge, J. Dvorak, J. Chomiak, L. Peterson, T. Graf-Baumann. Medical history and physical findings in football players of different ages and skill levels. American Journal of Sport Medicine; 28, 16-21, 2000.

[21] R. Neil, D. Fletcher, S. Hanton, SD Mellalieu. (Re)conceptualizing competition stress in sport performers. Sport \& Exercise Psychology Review; 3, 23-29, 2007.

[22] C. Robazza, L. Bortoli. Perceived impact of anger and anxiety on sporting performance in rugby players. Psychology of Sport \& Exercise, 2007; 8, 875-896, 2007.

[23] M. Sheard, J. Golby, A. van Wersch. Progress toward construct validation of the Sports Mental Toughness Questionnaire (SMTQ). European Journal of Psychological Assessment; 25(3), 186-193, 2009.

[24] CD. Spielberger, RL. Gorsuch, R. Lushene, PR. Vagg, GA. Jacobs. Manual for the State-Trait Anxiety Inventory. Palo Alto, CA: Consulting Psychologists Press, 1983.

[25] N. Öner, A. Le Compte. Durumluk-Sürekli Kaygl envanteri (Manual of State-Trait Anxiety Inventory), Boğaziçi Üniversitesi Matbaası: 71-74, 1983.

[26] BG. Tabachnik, L. Fidell. Using multivariate statistics, $6^{\text {th }}$ ed., Boston Pearson: 324-327, 2013.

[27] M. Andrew, HW. Grobbelaar, JC. Potgieter. Sport psychological skill levels and related psychosocial factors that distinguish between rugby union players of different participation levels. South Africa Journal of Research in Sport, Physical Education and Recreation; 29 (1), 1-14, 2007.

[28] RH. Cox, HS. Yoo. Playing position and psychological skills in American football. Journal of Sport Behavior; 18(3), 183-195, 1995. 
[29] M. Güçlü, M. Yaman, G. Çalışkan, H. Paşaoğlu, E. Işık, AF Tuncer. An examination of psychological and biochemical parameters of American football players and volleyball players: A Discriminate analysis. Anthropology; 25 (1,2): 160-167, 2016.

[30] Y. Tsutagawa. Psychological aptitude of shakaijin (company) rugby players: Characteristics of TSMI. Bulletin-Kobe City Colllege of Nursing; 13, 183-192, 1989

[31] P. Clough, D. Strycharczyk. Developing mental toughness: Improving performance, wellbeing and positive behaviors in others. London: Kogan Page, 61-86; 2012.

[32] DF. Gucciardi, S. Gordon, JA. Dimmock. Towards an understanding of mental toughness in Australian football.
Journal of Applied Sport Psychology; 20, 261-281, 2008.

[33] L. Hardy, J. Bell, S. Beattie. Mental toughness and reinforcement sensitivity: Preliminary evidence for a neuropsychological model of mental toughness. Journal of Personality; 8, 69-81, 2014.

[34] G. Jones, S. Hanton, D. Connaughton. What is this thing called mental toughness? An investigation with elite performers. Journal of Applied Sport Psychology; 14, 211 $224,2002$.

[35] R. Thelwell, N. Weston, I. Greenlees. Defining and understanding mental toughness in soccer. Journal of Applied Sport Psychology; 17, 326-332, 2005. 